Research

\title{
Second site escape of a T20-dependent HIV-I variant by a single amino acid change in the CD4 binding region of the envelope glycoprotein Chris E Baldwin and Ben Berkhout*
}

Address: Laboratory of Experimental Virology, Department of Medical Microbiology, Center for Infection and Immunity Amsterdam (CINIMA), Academic Medical Center of the University of Amsterdam, The Netherlands

Email: Chris E Baldwin - c.e.baldwin@amc.uva.nl; Ben Berkhout* - b.berkhout@amc.uva.nl

* Corresponding author

Published: 29 November 2006

Retrovirology 2006, 3:84 doi:10.1186/1742-4690-3-84

This article is available from: http://www.retrovirology.com/content/3/I/84

(c) 2006 Baldwin and Berkhout; licensee BioMed Central Ltd.

This is an Open Access article distributed under the terms of the Creative Commons Attribution License (http://creativecommons.org/licenses/by/2.0), which permits unrestricted use, distribution, and reproduction in any medium, provided the original work is properly cited.

\begin{abstract}
Background: We previously described the selection of a T20-dependent human immunodeficiency virus type-I (HIV-I) variant in a patient on T20 therapy. The fusion inhibitor T20 targets the viral envelope (Env) protein by blocking a conformational switch that is critical for viral entry into the host cell. T20-dependent viral entry is the result of 2 mutations in Env (GIA-SKY), creating a protein that undergoes a premature conformational switch, and the presence of T20 prevents this premature switch and rescues viral entry. In the present study, we performed 6 independent evolution experiments with the T20-dependent HIV-I variant in the absence of T20, with the aim to identify second site compensatory changes, which may provide new mechanistic insights into Env function and the T20-dependence mechanism.
\end{abstract}

Results: Escape variants with improved replication capacity appeared within 42 days in 5 evolution cultures. Strikingly, 3 cultures revealed the same single amino acid change in the CD4 binding region of Env (glycine at position 43I substituted for arginine: G43IR). This mutation was sufficient to abolish the T20-dependence phenotype and restore viral replication in the absence of T20. The GIA-SKY-G43IR escape variant produces an Env protein that exhibits reduced syncytia formation and reduced cell-cell fusion activity. The escape variant was more sensitive to an antibody acting on an early gp 4 I intermediate, suggesting that the G43 IR mutation helps preserve a pre-fusion Env conformation, similar to T20 action. The escape variant was also less sensitive to soluble CD4, suggesting a reduced CD4 receptor affinity.

Conclusion: The forced evolution experiments indicate that the premature conformational switch of the T20-dependent HIV-I Env variant (GIA-SKY) can be corrected by a second site mutation in Env (GIA-SKY-G43IR) that affects the interaction with the CD4 receptor.

\section{Background}

Host cell entry of Human Immunodeficiency Virus type-1 (HIV-1) is a critical step in the virus life cycle, which requires the recognition of the host cell receptor CD4 and a co-receptor, CCR5 or CXCR4, by the viral envelope (Env) glycoprotein. Env is arranged on the virus particle as trimeric spikes, comprising three gp120 and three gp41 molecules, anchored within the viral membrane via the 
gp41 transmembrane (TM) domain. Binding of the surface subunit gp120 to CD4 and a co-receptor on the T-cell surface triggers conformational changes in the Env complex, leading to the insertion of the hydrophobic N-terminal fusion peptide (FP) of gp41 into the target cell membrane (reviewed in [1]). Subsequent changes within the gp41 ectodomain (gp41e) involve two leucine zipperlike motifs; heptad repeat 1 (HR1) and heptad repeat 2 (HR2). Ultimately, HR1 and HR2 from three gp41 molecules assemble into a highly stable 6-helix bundle structure, which juxtaposes the viral and cellular membranes for the fusion event [2-4]. The change in free energy associated with this structural transition within gp4le is predicted to be sufficient to cause lipid mixing and membrane fusion $[5,6]$. Peptide fusion inhibitors that bind to one of the HR motifs can block this conformational switch, and thus inhibit viral entry [7-10].

The fusion inhibitor T20 (also called DP-178, Enfuvirtide and Fuzeon ${ }^{\mathrm{TM}}$ ) is the most clinically advanced drug of a new class of antivirals designed to inhibit viral entry [11]. T20 is a synthetic 36 amino acid peptide derived from the C-terminal region of HR2 $[8,12]$. By competitive binding to HR1, T20 blocks the formation of the 6-helix bundle, which is a prerequisite for membrane fusion and viral entry $[8,13]$. T20 has also been proposed to have additional target sites within Env; the $\mathrm{C} 4$ region of gp120 and the viral membrane proximal region of gp41e [14-18]. The C4 region in gp120 is involved in CD4 and co-receptor engagement and differences in how Env engages its receptors can influence T20 sensitivity $[14,15]$.

HIV-1 variants that are resistant to this compound have been described and resistance mutations have been identified within the viral quasispecies of patients on T20 therapy [19-24]. Sequence analysis of the resistant viral population revealed the acquisition of mutations mainly within a stretch of three HR1 amino acids, glycine-isoleucine-valine (further referred to as the GIV sequence, HXB2 amino acid positions 547 to 549 of gp160). In addition, mutations flanking this region (amino acids 550-556 of HR1) have also been proposed to confer a distinct level of resistance to T20 [25-27].

Recently, we performed a genetic analysis of the entire HIV-1 gp41e of the viral population from a patient that failed on T20 therapy [20]. Sequence analysis revealed the acquisition of the T20-resistance mutation GIA (GIV to GIA; mutated amino acid underlined) in HR1. We also documented a subsequent change in the three amino acid SNY sequence of the HR2 domain (SNY to SKY). We demonstrated that the HR1-HR2 double mutant (GIA-SY), which dominated the viral population after 32 weeks of therapy, was not only highly resistant to T20, but also critically dependent on the T20 peptide for its replication. We proposed a mechanistic model that supports this novel feature of drug-dependent viral entry. Briefly, resistance to T20 is caused by the GIA mutation in HR1, which weakens the interaction with both T20 (resistance) and HR2 (gp41 6-helix bundle formation). Reduced HR1-T20 affinity explains the resistance phenotype, but reduced HR1-HR2 affinity negatively impacts Env-mediated fusion and HIV-1 fitness [20,28]. The T20-dependence phenotype is caused by the introduction of the SKY mutation in HR2, which attempts to re-stabilise the HR1-HR2 affinity defect caused by the GIA resistance mutation in HR1. However, the SKY mutation creates a hyperfusogenic Env-gp41 molecule that prematurely undergoes the conformational switch to a later fusion intermediate or the 6-helix bundle. T20 is able to prevent this premature switch by preserving and earlier pre-fusion conformation, enabling gp41 to undergo the necessary conformational switch at the correct moment in the fusion process. In the present study, we performed forced evolution experiments with the T20-dependent virus in the absence of the T20 peptide with the aim to identify second site compensatory changes, which could provide new mechanistic insights into Env function and the T20dependence mechanism.

\section{Results \\ The T20-dependent virus evolves to T20-independence}

We performed forced evolution experiments with the T20dependent virus (GIA-SKY) in the absence of the T20 peptide. We previously demonstrated the power of the forced evolution approach in diverse HIV-1 studies [29-31]. Evolution cultures were started by transfection of the GIA-SKY molecular clone into the SupT1 T-cell line. Viral replication was monitored over a 42 day period and virus plus cell samples were taken at several times in the course of the experiment. Efficient viral spread was measured via CA-p24 determination and consequently virus-induced syncytia were observed in 5 of the 6 evolution cultures. The replication capacity of these evolved virus samples was assayed by infection of fresh SupT1 cells with an equal amount of virus. We included the T20-dependent starting virus (GIA-SKY) as well as the wild-type virus (GIV-SNY) as controls (Fig. 1A). Evolution cultures 1, 5 and 6 replicated very efficiently, producing CA-p24 to levels above that of the wild-type and evolution cultures 2 and 4 produced CA-p24 levels similar to the wild-type, confirming the presence of replication competent viral populations that no longer require the T20 peptide. Only evolution culture 3 showed no obvious sign of viral escape.

\section{Genotypic analysis of the escaped viruses}

One may anticipate that the phenotypic reversion would be caused by back-mutation of the SKY sequence in HR2 to the wild-type SNY sequence, which would remove the 


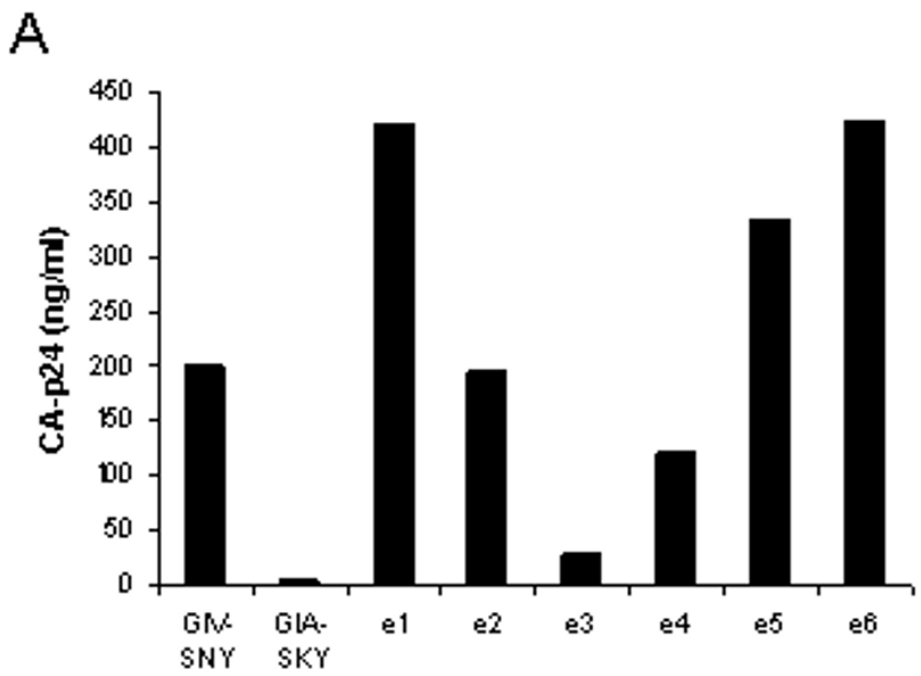

B

\begin{tabular}{|c|c|c|c|c|c|}
\hline & & $g p 120$ & $g p 41$ & Replication (-T20) & Syncytia formation \\
\hline \multicolumn{2}{|c|}{ GIA-SKYY incus } & - & $\cdot$ & $-1 /$ & $++/ t+t$ \\
\hline \multirow{6}{*}{$\begin{array}{l}\text { Evolution } \\
\text { cutures } \\
\text { (day 42) }\end{array}$} & e1 & G431R & - & ++++ & +++ \\
\hline & e2 & A221V & - & $*+$ & $4+4$ \\
\hline & e3 & - & - & + & $+\bullet$ \\
\hline & $e 4$ & G431R & - & $*+$ & $+*+*+$ \\
\hline & e5 & G431R & $\cdot$ & ++++ & +++++ \\
\hline & e6 & - & $\begin{array}{l}\text { QS67RR } \\
\text { N750NVT } \\
\text { Y762Y/C } \\
\text { Q7990/H }\end{array}$ & $+++\infty$ & $++t+t$ \\
\hline
\end{tabular}

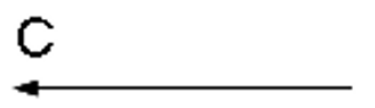

HIV-1 envelope gp160 precursor

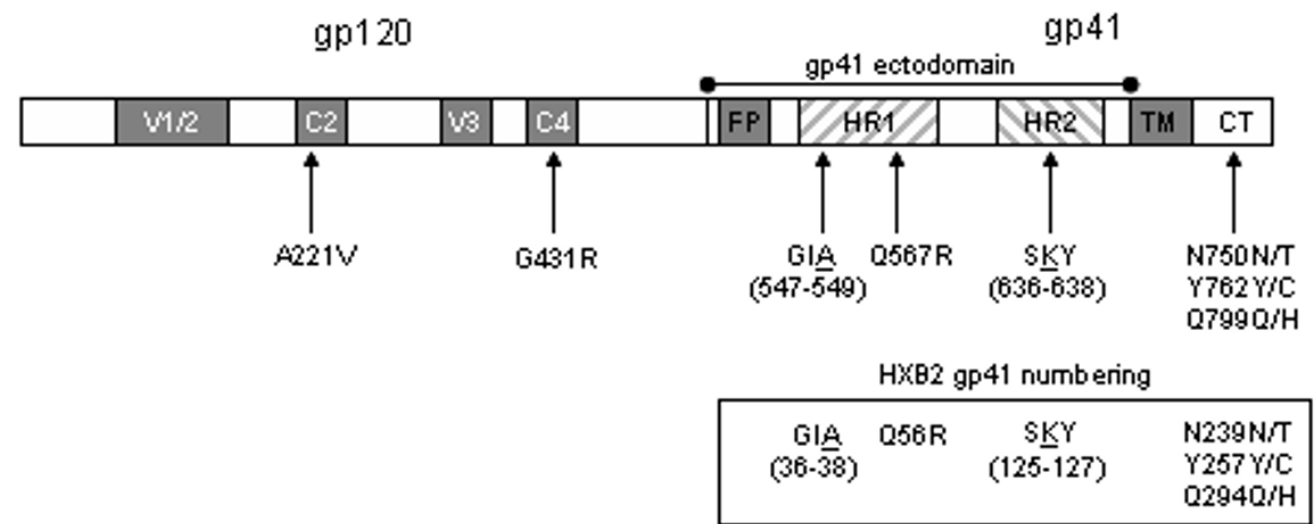

Figure I

Evolution of the T20-dependent HIV-I variant. (A) Replication of wild-type (GIV-SNY), T20-dependent (GIA-SKY) and HIV-I variants obtained in evolution cultures in the absence of T20. Bars represent CA-p24 values at day 4 post-infection, which represent the relative differences in replication capacity. Infection of fresh SupTI cells was performed with an equal amount of the viral stocks obtained at day 42 of evolution. (B) Summary of observed mutations, replication capacity and syncytia formation of the six evolution cultures after 42 days of evolution. Replication without T20 and syncytia formation represent relative differences observed in infection experiment displayed in IA (-, no replication or syncytia; ++++, high replication or all cells involved in syncytia). (C) Schematic of mutations in the Env protein. The complete Env gene is shown (not to scale) with the location of the original GIA-SKY mutations and the second site changes selected in the evolution cultures. The G43 IR change that was selected in multiple cultures is marked in bold. Both gp 160 and gp4I HxB2 numbering references are included. 
T20-dependence phenotype. This would produce the GIA single mutant, which is T20-resistant, but no longer dependent on T20 [20]. Although this may seem the most likely outcome, second site compensatory changes elsewhere in the Env glycoprotein would also be a possibility. In order to determine the sequence changes in these phenotypic revertants, we PCR-amplified the entire Env gene from cellular proviral DNA and analysed the sequence for mutational changes (Fig. 1B and 1C). No changes in or directly adjacent to the GIA motif in HR1 or the SKY motif in HR2 were detected. Evolution culture 3, which showed no sign of viral escape, did not reveal any mutational changes within the entire Env gene. All other cultures that yielded an escape viral population showed at least one mutation in the Env gene. Evolution culture 2 showed a single amino acid change $\mathrm{A} 221 \mathrm{~V}$ in the $\mathrm{C} 2$ region of gp120. This amino acid is highly conserved in natural subtype B isolates [52], indicating that it plays an important role in Env function. Evolution culture 6 acquired multiple mutations in gp41 but no changes were seen within gp120. One change was observed in HR1 (Q567R) and 3 partial changes in the cytoplasmic tail (CT), N750N/T, Y762Y/C and Q799Q/H. Of most interest were evolution cultures 1,4 and 5 that all acquired the same point mutation (G431R; all identical codon changes GGA-to-AGA), with no changes elsewhere in the Env protein. The G431R mutation is positioned in the $\mathrm{C} 4$ region of gp120, which plays a critical role in CD4 and co-receptor engagement [32-35]. Amino acid position 431 is highly conserved in natural subtype B isolates [52], which suggests that it plays
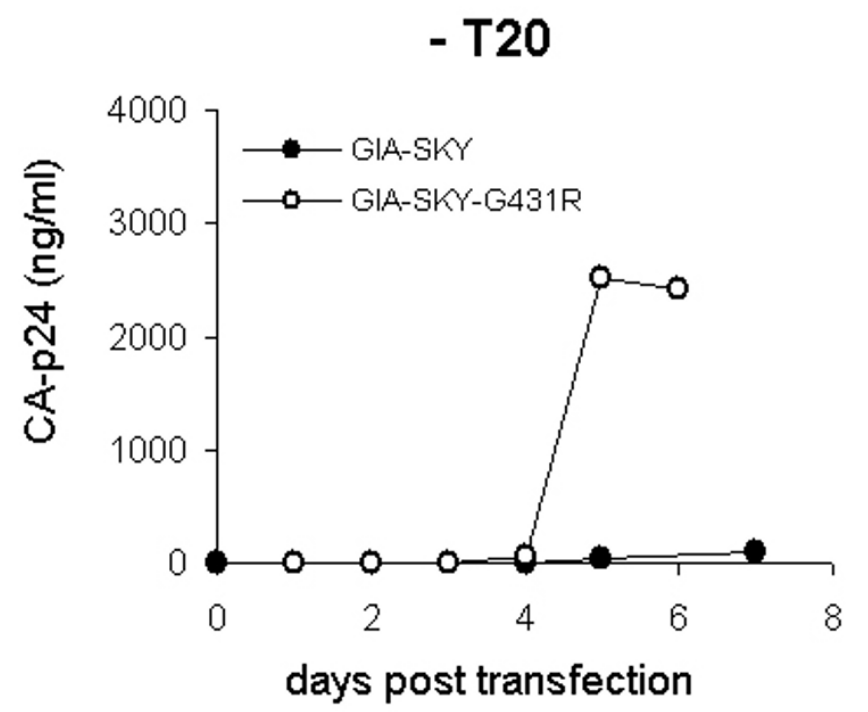

an important role in Env function. It is striking that the same mutation was selected in 3 independent evolution cultures, suggesting this mutation may play a key role in the phenotypic reversion to T20-independence. We therefore decided to investigate this revertant (GIA-SKYG431R) in more detail.

\section{The G43IR mutation rescues the T20-dependent virus}

The G431R mutation was introduced into the GIA-SKY molecular clone and tested for its impact on viral replication and T20 resistance/dependence. Viral DNA constructs were transfected into SupT1 cells and cultured in the presence or absence of T20 (Fig. 2). Replication of the GIA-SKY virus was dependent on the T20 peptide as previously reported [20]. The GIA-SKY-G431R revertant was able to replicate in the absence of T20, confirming that the G431R mutation in gp120 is sufficient for the loss of the T20-dependent phenotype. The GIA-SKY-G431R revertant is resistant to T20 because it still contains the crucial T20resistance mutation GIA.

We next tested the hypothesis that the G431R mutation in the GIA-SKY-G431R revertant represents a compensatory mutation that reduces or controls the structural transition in the GIA-SKY Env protein. We thus propose that the G431R mutation may offer a similar mechanistic check as the T20 peptide and preserve a pre-fusion intermediate necessary for correct gp41 conformational changes. To test this, we performed a cell-cell fusion assay, which specifically measures Env fusion activity (Fig. 3). In this assay,

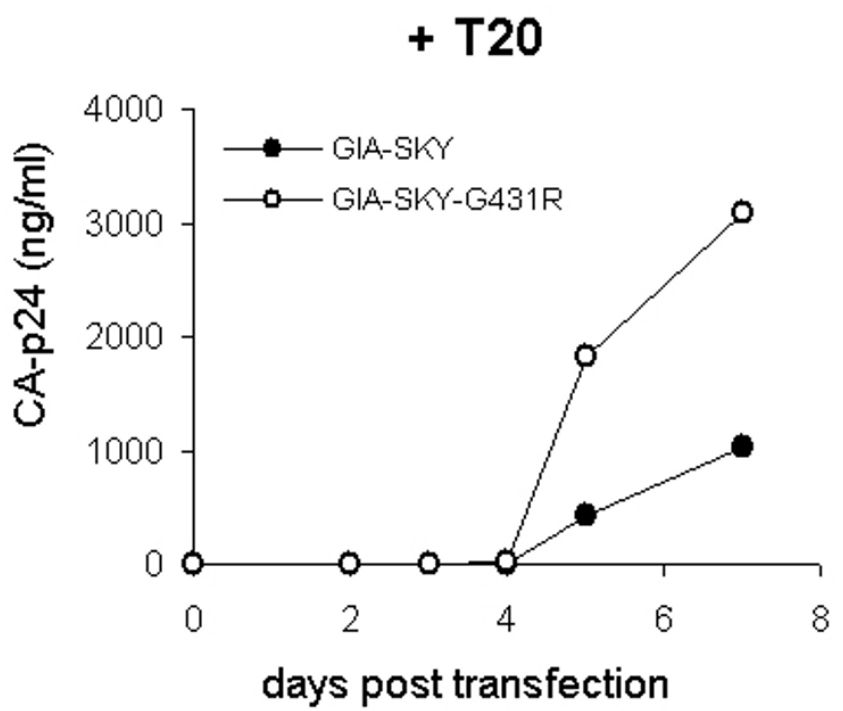

\section{Figure 2}

Replication of the T20-dependent GIA-SKY mutant and the GIA-SKY-G43 IR revertant virus. Molecular clones were transfected in SupTI cells that were cultured with $(100 \mathrm{ng} / \mathrm{ml})$ and without T20. Virus replication curves were made over a 7-day period. Closed circles represent the original GIA-SKY mutant virus and open circles the GIA-SKY-G43 IR revertant.

This is a representative experiment, similar results were observed in 3 repeated experiments including results in figure 4 , top. 
one cell expresses the wild-type or mutant Env protein and the other cell the appropriate receptors (CD4 and CXCR4). Fusion was scored by the formation of syncytia. In addition, we introduced an LTR-luciferase reporter in the acceptor cell that is activated upon cell fusion by Tat protein that is expressed in the donor cell. We measured dramatically reduced fusion activity (syncytia and luciferase counts) for the GIA-SKY-G431R revertant compared to the GIA-SKY mutant (black bars) (Fig. 3). Addition of T20 similarly reduces the fusogenicity of the GIA-SKY mutant (shaded bars), although the effect is more modest than that of the G431R reversion as we only used $20 \mathrm{ng} /$ $\mathrm{ml}$ of T20. However, we previously demonstrated that T20 has a dose dependent inhibitory effect in this assay, with higher concentrations significantly blocking cell-cell fusion [20]. This result is consistent with the idea that both the exogenous T20 peptide and the endogenous G431R mutation have a moderating impact on the hyperfusogenic GIA-SKY Env mutant. They are both able to control or down-regulated the hyper-fusogenicity of the GIASKY Env protein, which normally undergoes a premature conformational switch to the 6-helix bundle structure.

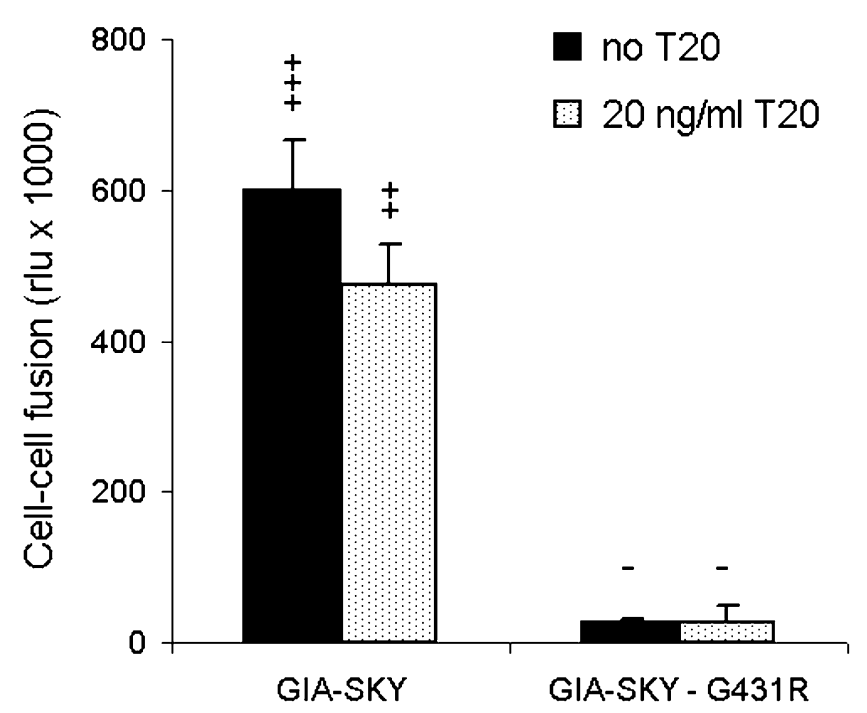

Figure 3

Cell-cell fusion assay with the GIA-SKY mutant and the GIA-SKY-G43 I R revertant. SupT I cells were transfected with the HIV-I pLAl constructs indicated below the $X$-axis. One day later, transfected cells were mixed with SupTI cells containing a Tat-responsive LTR-luciferase reporter gene construct with $(20 \mathrm{ng} / \mathrm{ml})$ or without T20. After 24 hours, formation of syncytia was analysed by light microscopy (-, no syncytia; ++++, all cells involved in syncytia) and quantitated by measurement of luciferase activity in cell extracts.

\section{Influence of amino acid 43 I on Env function}

We decided to investigate the effect of amino acid 431 in more detail. Because the $\mathrm{C} 4$ region has been implicated as a contact site for host cell CD4 and co-receptor engagement, amino acid changes in this region may affect the ability of Env to interact with CD4 and/or co-receptor and thereby influence the cell-cell and virus-cell interactions [32-36]. The X-ray structure of the HIV-1 Env protein is consistent with this possibility because amino acid 431 is located within the critical CD4 binding site [37,38]. Alternatively, changes at amino acid 431 may affect the EnvCD4 interaction in a more indirect manner through an effect on the folding of this complex glycoprotein.

The T20-independent phenotype is caused by the replacement of a neutral glycine with a positively charged arginine at position 431 . We therefore wanted to test what effect the introduction of a negatively charged glutamic acid at this position would have on the GIA-SKY mutant. We constructed the molecular clone GIA-SKY-G431E and tested the ability of this mutant to replicate with and without T20. Transfection of this molecular clone into SupT1 cells resulted in a replication defective virus both with and without T20 (Fig. 4, top). This result demonstrates that amino acid position 431 is critical for Env function and that not any substitution at this position will rescue the GIA-SKY mutant.

We next tested the effect of G431R and G431E on the wild-type virus (GIV-SNY) (Fig. 4, bottom). As expected, replication of the wild-type was strongly inhibited by T20. Introduction of the positive arginine (G431R) resulted in increased replication of the wild-type in the absence of T20. This may be due to the severe syncytia-formation defect that this mutant exhibits in cell culture on SupT1 cells, which allows the cells to survive longer and hence allows the virus to replicate freely and subsequently produce higher quantities of CA-p24 (see discussion for details). Introduction of the negatively charged glutamic acid (G431E) completely abolished viral replication of the wild-type, both with and without T20, as observed in the context of the GIA-SKY virus. However, when an alternative neutral amino acid (alanine which is the most analogous amino acid to the endogenous glycine; G431A) was introduced into the wild-type virus, replication and syncytia formation was re-established. As expected, all C4 mutants in the context of the wild-type sequence were totally sensitive to the T20 peptide (Fig. 4, bottom/right).

\section{G43 IR prevents an early gp4 I conformational switch by counteracting hyper-fusogenicity}

We further analysed the molecular clones in a cell-cell fusion assay to directly measure their effect on Env function (Fig. 5). As previously reported, GIA-SKY Env is hyper-fusogenic; approximately $1.2-1.5$ fold more 
- T20

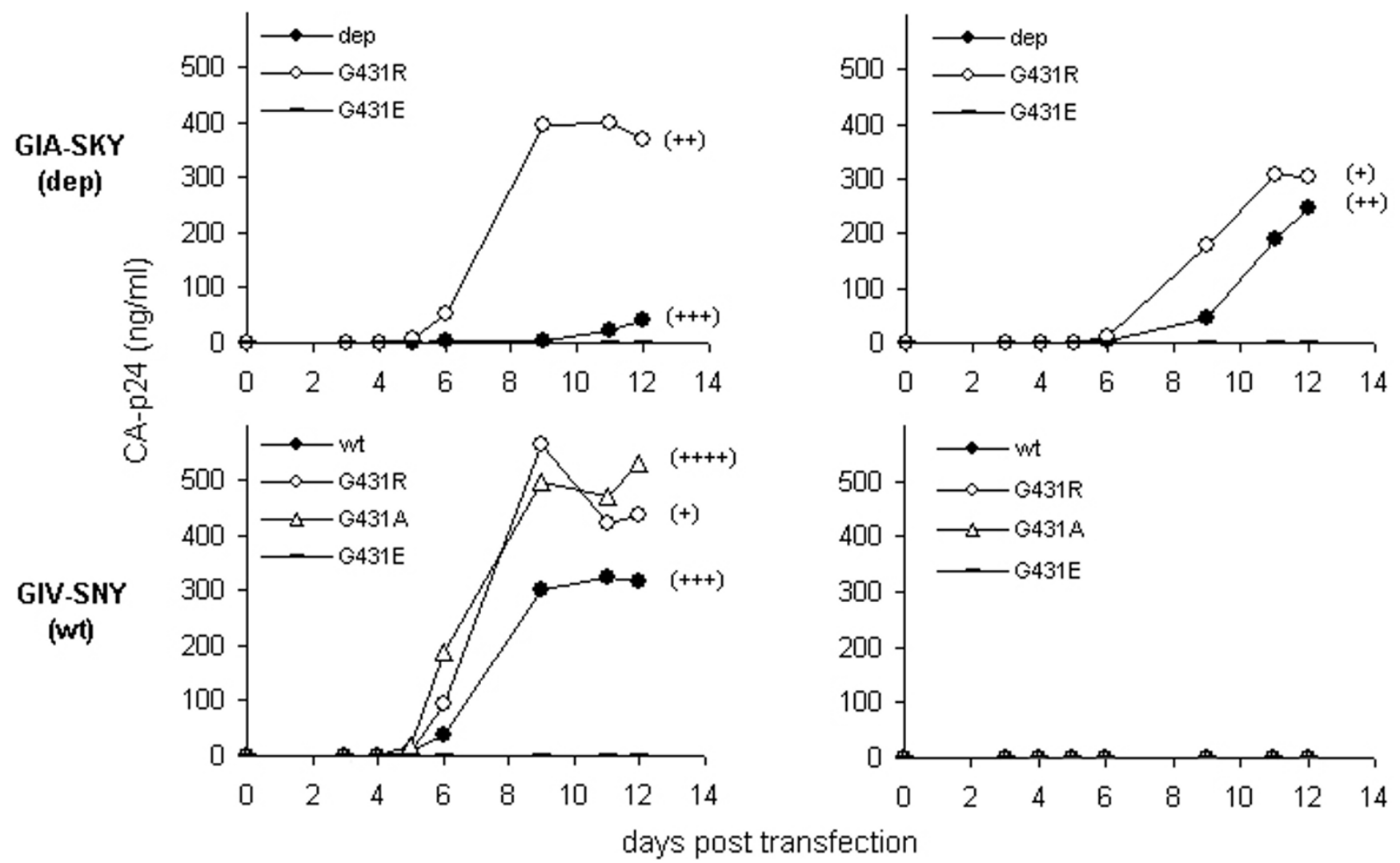

Figure 4

Replication of G43 I-mutated viruses. SupTI cells were transfected with the T20-dependent (GIA-SKY, top panel) and the wild-type (GIV-SNY, lower panel) with variation at position $43 \mathrm{I}$ as indicated. Replication was measured both in the presence $(100 \mathrm{ng} / \mathrm{ml})$ and absence of T20. Virus replication curves were made over a I2-day period. Syncytia formation at day I 2 was recorded (-, no syncytia; ++++, all cells involved in syncytia). Position 43I variation in the GIA-SKY T20-dependent virus (top) and the wild-type GIV-SNY virus (bottom): wild-type 43 I G (closed circles), G43IR (open circles), G43IE (dashes) and G43 IA (open triangles, in wild-type only).

fusogenic then the wild-type (GIV-SNY) Env and T20 can control this fusion step by inhibiting the wild-type and controlling the hyper-fusogenic activity of the GIA-SKY Env [20]. Indeed, we were able to reproduce this result and show that $20 \mathrm{ng} / \mathrm{ml} \mathrm{T20}$ is sufficient to lower the fusogenicity of GIA-SKY back to levels of the wild-type virus. Most importantly, we also measured reduced Env function for the GIA-SKY-G431R revertant and this inhibition was also observed in the presence of T20. G431R had the same effect on Env function in the context of wildtype and this mutant was totally inhibited by T20 as it does not contain the GIA T20-resistance mutation. Introduction of the negatively charged glutamic acid residue completely abolished cell-cell fusion activity of the wildtype virus, consistent with the replication curves of these mutants in Figure 4. The neutral alanine residue in the wild-type context showed intermediate fusion activity, again consistent with the results of replication and syncytia assays shown in Figure 4.

We have shown that GIA-SKY replication in the absence of T20 is facilitated by the introduction of the G431R mutation in the gp120 C4 region. This finding is consistent with our model that GIA-SKY is dead due to an overly aggressive (hyper-fusogenic) Env protein. We propose that G431R negatively affects the Env/CD4 interaction as a means to prevent the abortive premature switch of the 6helix bundle. To test this, we measured the sensitivity of the wild-type (GIV-SNY) and revertant (GIA-SKY-G431R) viruses to the soluble form of $\mathrm{CD} 4$ (sCD4), using a standard virus replication assay to mimic the evolutionary setting (Fig. 6, left panel). sCD4 is able to inhibit virus entry by competitively binding to the Env-gp120 C4 region of HIV-1 before the virus engages the cellular CD4 receptor 


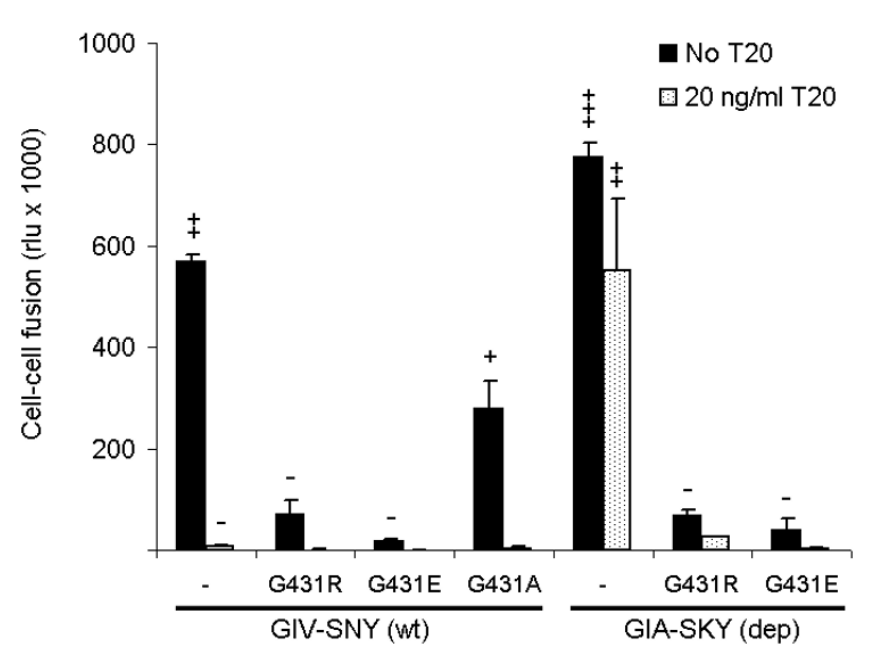

Figure 5

Cell-cell fusion assay with the G43 I-mutated Env variants. Assay of wild-type (GIV-SNY) and T20-dependent (GIA-SKY) viruses with position 43 I variation as indicated, in the presence $(20 \mathrm{ng} / \mathrm{ml})$ and absence of T20. SupTI cells were transfected with the mutants indicated below the $X$ axis. One day later, transfected cells were mixed with SupT I cells containing a Tat-responsive LTR-luciferase reporter gene construct with $(20 \mathrm{ng} / \mathrm{ml})$ or without T20. After 24 hours, formation of syncytia was analysed by light microscopy (-, no syncytia; ++++, all cells involved in syncytia) and quantitated by measurement of luciferase activity in cell extracts.

[39]. The revertant, which produces significantly more CA-p24 compared to the wild-type (see discussion), was less sensitive (more resistant) to $\mathrm{sCD} 4$ than the wild-type, indicating that it has reduced CD4 binding affinity. At the highest sCD4 concentration $(10 \mu \mathrm{g} / \mathrm{ml})$, wild-type was inhibited to $23 \%$, whereas the revertant remained at $80 \%$ replication capacity. At an intermediate $1 \mu \mathrm{g} / \mathrm{ml} \mathrm{sCD} 4$ concentration, wild-type was inhibited to $60 \%$ however; this concentration had no inhibitory effect on the revertant.

We further wanted to analyse the gp41 structure of GIASKY-G431R revertant and see if this virus is more sensitive to HR1 inhibitors, which would suggest that gp41 is in an "open" or "loose" conformation. For this, we used a gp41 antibody that binds to an open HR1 pre-fusion intermediate. This D5-IgG1 antibody specifically targets the gp41 HR1 region and can bind to a region slightly upstream of the GIA motif [40]. Because the revertant contains the GIA T20-resistant mutation, using T20 is not an option as this revertant is resistant to the peptide (Fig. 2). The revertant was considerably more sensitive (less resistant) to the D5IgG1 antibody than the wild-type. At the lowest concentration $(5 \mu \mathrm{g} / \mathrm{ml})$, wild-type was unaffected, whereas the revertant was inhibited to $45 \%$ replication capacity. At an intermediate $50 \mu \mathrm{g} / \mathrm{ml}$ D5-IgG1 concentration, the revertant was significantly inhibited to $17 \%$ replication capacity, whereas the wild-type was inhibited to $78 \%$. This result suggests that the HR1 domain is exposed and more susceptible to the inhibitor in the revertant Env protein. The combined results of the reduced sensitivity to sCD4 and increased sensitivity to D5-IgG1 suggest that the G431R mutation partially restores gp41 function of the Env protein by modulating the Env-CD4 interaction and 6-helix bundle formation.

\section{Conclusion}

In this study, we performed forced evolution experiments with a T20-dependent virus [20] in the absence of T20 with the aim to identify second site compensatory changes, which could provide new mechanistic insights into Env function and the T20-dependence mechanism. Escape variants with improved viral replication were selected in 5 independent evolution cultures. We sequenced the complete HIV-1 Env gene and observed several mutations. Strikingly, 3 evolution cultures contained identical escape variants with the same glycine-toarginine substitution at position 431 of Env (all identical codon changes GGA-to- $\underline{A G A) . ~ G l y c i n e ~} 431$ is located in the CD4 binding region of Env gp120 and is highly conserved among natural HIV-1 isolates, suggesting it plays a key role in CD4 receptor engagement [32-35]. In order to directly test the effect of the G431R mutation, we introduced it back into the original GIA-SKY T20-dependent molecular clone. Replication assays in SupT1 cells confirmed that the G431R mutation is sufficient to restore replication in the absence of $\mathrm{T} 20$.

One may anticipate that phenotypic reversion of the T20dependent GIA-SKY virus would occur via back-mutation of the SKY mutation in HR2 to either SNY or NNY to remove the T20-dependence phenotype. This would produce the GIA single mutant, which is T20-resistant, but not T20-dependent [20]. However, the GIA mutant has diminished replication kinetics, which would place this escape variant at a disadvantage to other escape variants $[20,28]$. In addition, this evolution route requires a relatively difficult transversion type of mutation (G-to-T), whereas the G431R mutation is made by a simple transition type mutation (G-to-A) [41-43]. Back-mutation of the GIA sequence to GIV is also not an option as the SKY single mutant is a dead virus [20]. This implies that the G431R substitution is selected as an alternative solution to the conformational gp41 defect of the GIA-SKY mutant, which is normally controlled by T20.

We previously reported that T20 is able to control or preserve an early pre-fusion conformation of gp41 so that, after CD4 and co-receptor engagement, gp41 conformational changes can occur and virus/cell fusion and entry 

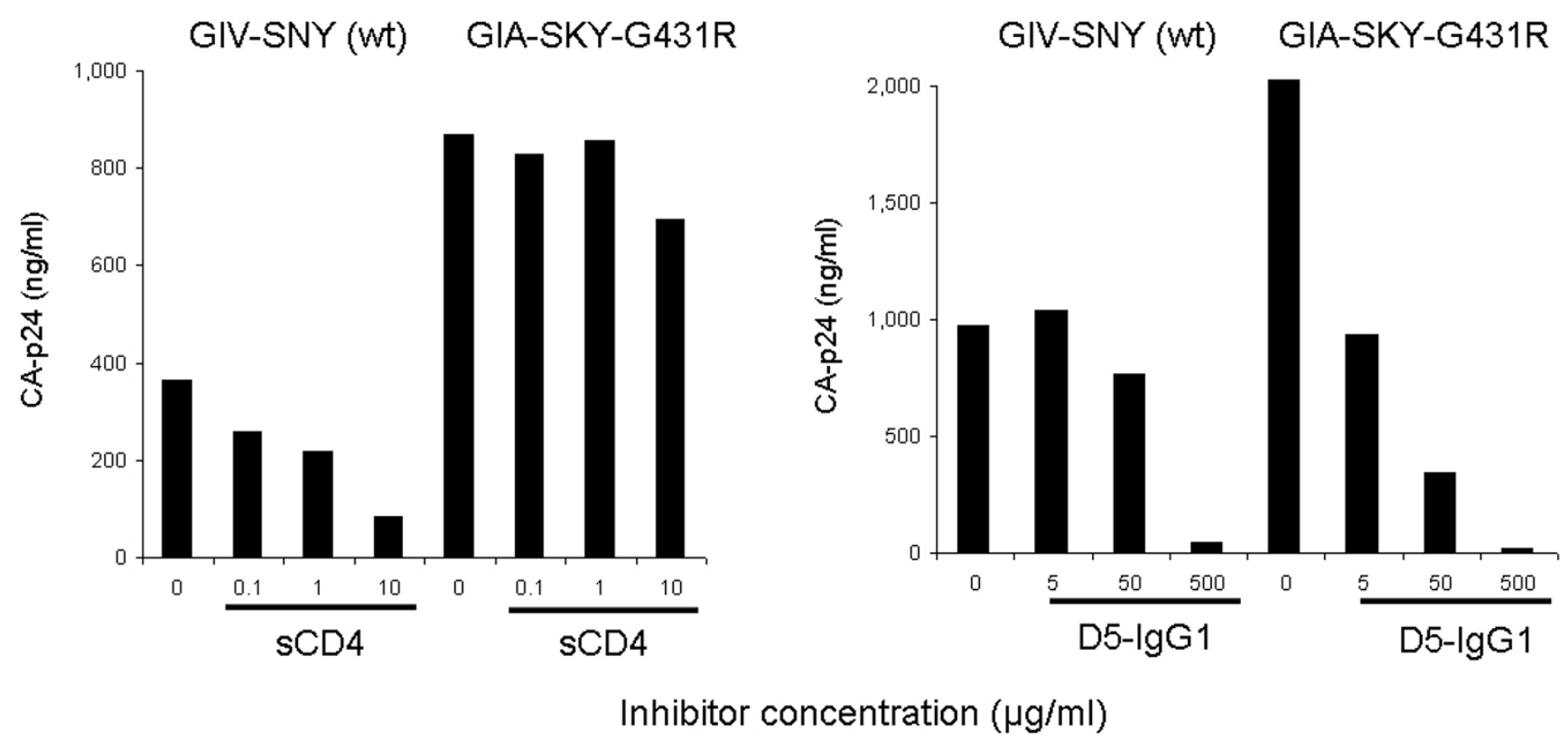

Figure 6

Sensitivity of wild-type GIV-SNY and GIA-SKY-G43 I R revertant viruses to sCD4 and D5-IgGI gp4I antibody. Bars represent CA-p24 values at day 6 post-transfection, which represent the relative differences in replication capacity in the presence of the sCD4 inhibitor and the D5-lgGI antibody for the wild-type virus compared to the revertant virus. This is a representative experiment, similar results were observed in 2 independent experiments.

can subsequently take place [20]. The G431R mutation could similarly restore gp 41 function by preventing the abortive premature switch in gp41. We indeed measured significantly reduced sensitivity to the sCD4 inhibitor (Fig. 6, left panel). Because the $\mathrm{C} 4$ region has been implicated as a contact site for CD4 receptor on the host cell surface, these changes may affect the ability of Env to interact with CD4 [32-35]. The X-ray structure of the HIV1 Env protein is consistent with this possibility because amino acid 431 is located within the critical CD4 binding domain $[37,38]$. Alternatively, the amino acid 431 change may affect the Env-CD4 interaction in a more indirect manner through an effect on the folding of this complex glycoprotein. To test this, we used a gp41 antibody (D5IgG1) which targets the HR1 region of the pre-fusion gp41 conformation. For this antibody to have a more potent inhibitory activity, the HR1 region of gp41 would need to be more accessible and hence be in an "open" state, free from bound HR2 [40]. We indeed measured increased sensitivity to the D5-IgG1 antibody (Fig. 6, right panel). The combined results of the reduced sensitivity to sCD4 and increased sensitivity to D5-IgG1 suggest that the G431R mutation partially restores gp41 function of this Env protein by modifying the Env-CD4 interaction and gp41 conformational changes, thus preventing or modulating the premature switch to the 6-helix bundle similar to the effect of the T20 peptide on this mutant.
Interestingly, the G431R mutation has previously been selected in long-term cultures of a translationally impaired HIV-1 mutant [44,45]. Consistent with our current results, reduced syncytia formation and increase CAp24 production compared to the wild-type virus was also scored. This phenotype allows the infected SupT1 cells to survive longer, thus producing more viral progeny. This loss of fusogenicity via Env-CD4 interaction was measured via a cell-cell fusion assay and provides an obvious advantage in the context of our T20-dependent GIA-SKY mutant which is overly aggressive at engaging target cells, resulting in premature syncytia formation [20]. Beddows et al. [17] recently reported a similar finding where a C4 mutant Env showed increased sensitivity to Env antibodies, reduced infectivity and adaptation to SupT1 cells.

In 1987, Kowalski et al. [46] demonstrated that insertional mutations in gp41 HR2 region disrupt the gp120gp41 interaction and suggested that the HR2 region is a "touch point" for gp41-gp120 interactions. More recently, a strong link between the $\mathrm{C} 4$ region of gp120 and the gp41-HR2 region (including the T20 sequence) has been proposed by a number of research groups [16-18,46]. Short peptides designed to mimic the C4 region in gp120 have the ability to suppress the T20 inhibitory effect either by preventing T20 from binding to the $\mathrm{C} 4$ region in gp 120 and/or by modulating gp41 conformational changes via 
interaction with the HR2 region in gp41. Alam et al. [16] found an HR2/T20 peptide-binding site on soluble HIV-1 recombinant gp120. Furthermore, they demonstrated that binding of T20 was induced by sCD4 and anti-gp 120 human mAb A32 and was inhibited by the HIV-1 coreceptor-binding site $\mathrm{mAb} 17 \mathrm{~b}$ and $\mathrm{C} 4$ peptides. Their results strongly suggest a link between the $\mathrm{C} 4$ region in gp120 and the gp41-HR2 region. They suggested that a stabilized HR2/Env conjugate may be a possible HIV-1 vaccine candidate with the potential for inducing antibodies against transiently exposed epitopes on HIV-1 Env. It would be interesting to investigate if our GIA-SKY-G431R revertant, which has reduced sensitivity to sCD4 and increased sensitivity to HR1 antibodies, may be such a possible vaccine candidate.

We previously incorporated the T20-dependent phenotype in the doxycycline (dox)-dependent HIV-rtTA virus that was described as a conditional live vaccine strain $[47,48]$. Our current results indicate that the T20-control may be lost by a single mutation in the Env gene (i.e. G341R). However, we forced this evolutionary escape route by culturing the virus without T20. Furthermore, the dox-control will be used such that the virus is replicating only transiently to induce the immune system and this will restrict evolution and thus avoid unwanted evolutionary paths.

\section{Materials and methods \\ Cell transfection and CA-p24 determination}

The SupT1 T-cell line was maintained in RPMI 1640 supplemented with $10 \%$ fetal calf serum (FCS), penicillin and streptomycin (both at 100 units $/ \mathrm{ml}$ ) and incubated at $37^{\circ} \mathrm{C}$ with $5 \% \mathrm{CO}_{2}$. SupT1 cells were transfected with HIV-1 molecular clones by means of electroporation. Briefly, $5 \times 10^{6}$ cells were washed in RPMI 1640 containing $20 \%$ FCS, mixed with $0.5-5 \mu \mathrm{g}$ of DNA in $0.4-\mathrm{cm}$ cuvettes, and electroporated at $250 \mathrm{~V}$ and $975 \mu \mathrm{F}$, followed by resuspension of cells in RPMI 1640 with $10 \%$ FCS. The transfected cells were split 24 hours post-transfection and incubated with or without inhibitor or antibody. CA-p24 production was determined from culture supernatant taken at various days post-transfection using a CA-p24 antigen capture enzyme-linked immunosorbant assay as previously described [49].

\section{Virus evolution in cell culture}

For the selection of revertant viruses, SupT1 cells were transfected with $1 \mu \mathrm{g}$ DNA of the GIA-SKY molecular clone [20]. Transfected cells were split at approximately 16 hours post transfection into 6 separate culture flasks and $0.5 \times 10^{6}$ fresh SupT1 cells were added in order to start the 6 independent evolution cultures. We initially split $100 \mu \mathrm{l}$ of cells plus supernatant when required onto uninfected SupT1 cells. When HIV-induced cytopathic effects and increased CA-p24 production were apparent, virus replication was maintained by passage of cell-free culture supernatant onto uninfected SupT1 cells. Initially, we used $100 \mu \mathrm{l}$ cell-free culture supernatant to infect $5 \mathrm{ml}$ fresh SupT1 cells (approximately $0.5 \times 10^{6}$ cells), but we gradually used less culture supernatant per passage. Cells and supernatant samples were taken at regular time points and stored at $-70^{\circ} \mathrm{C}$.

\section{Proviral DNA isolation, PCR amplification and sequencing} HIV-1 infected cells ( $1 \mathrm{ml}$ culture) were pelleted by centrifugation at $4000 \mathrm{rpm}$ for $4 \mathrm{~min}$ and the supernatant was analysed for CA-p24 contents and stored at $-70^{\circ} \mathrm{C}$. The cell pellet was lysed in $10 \mathrm{mM}$ Tris- $\mathrm{HCl}$ (pH 8.0), $1 \mathrm{mM}$ EDTA, $0.5 \%$ Tween 20 and incubated with $500 \mu$ g Proteinase $\mathrm{K} / \mathrm{ml}$ at $56^{\circ} \mathrm{C}$ for $60 \mathrm{~min}$ and heat-inactivated at $95^{\circ} \mathrm{C}$ for $10 \mathrm{~min}$. Proviral DNA sequences of the entire Env gene were PCR-amplified from solubilized cellular DNA $(5 \mu \mathrm{l})$ using the Expand High Fidelity PCR System (Roche). Briefly, after incubation for $5 \mathrm{~min}$ at $94^{\circ} \mathrm{C}$, the reaction mixture was subjected to 35 PCR cycles in a type 9700 DNA thermal cycler (Perkin Elmer Cetus), with each cycle including a denaturation step for $30 \mathrm{sec}$ at $94^{\circ} \mathrm{C}$, an annealing step for $30 \mathrm{sec}$ at $60^{\circ} \mathrm{C}$ and an extension step for $3 \mathrm{~min}$ at $68^{\circ} \mathrm{C}$. This was followed by a final extension step of $7 \mathrm{~min}$ at $68^{\circ} \mathrm{C}$. The PCR was performed with $50 \mathrm{ng}$ sense and antisense primers (WS1, 5'-ATAAGCTTAGCAGAAGACA-3', and 3'envMD4, 5'-GCAAAATCCTTTCCAAGCCC-3') in a $50 \mu \mathrm{l}$ PCR reaction. DNA products were analysed on a $1 \%$ agarose gel that was pre-stained with ethidium bromide. PCR products were sequenced directly using the DNA Big Dye Terminator Sequencing Kit (ABI, Foster City, California) and an ABI 377 automated sequencer.

\section{Construction of LAI molecular clones}

The full-length molecular HIV-1 clone pLAI was used to produce wild-type and mutant viruses [50]. We already described the wild-type variant with the GIV-SNY sequence as observed in the patient isolate in place of the GIV-NNY sequence that is present in the LAI molecular clone [20]. The plasmid pRS1, designed to subclone mutant Env genes, was generated as previously described [51]. Mutations were introduced in pRS1 using the Quickchange mutagenesis kit (Stratagene, La Jolla, CA, USA) and the entire Env gene was verified by DNA sequencing. Mutant Env genes in pRS1 were cloned back into pLAI as SalI-BamHI fragments. These included the G431R, G431E and G431A mutations in the $\mathrm{C} 4$ region in combination with the gp41 wild-type GIV-SNY or mutant GIA-SKY.

\section{Cell-cell fusion assay}

SupT1 cells $\left(5 \times 10^{6}\right)$ were transfected with $5 \mu \mathrm{g}$ of the indicated pLAI variants and/or the pcDNA3-Tat expression plasmid as described above. The cells were cultured 
for approximately 18 hours, spun at $1200 \mathrm{rpm}$ for $10 \mathrm{~min}$ and resuspended in fresh media containing saquinavir (1 $\mu \mathrm{M}$ final concentration $)$, with $(20 \mathrm{ng} / \mathrm{ml})$ or without $\mathrm{T} 20$. Cells were subsequently mixed with SupT1 cells that were transfected the previous day with $5 \mu \mathrm{g}$ LTR-luciferase reporter plasmid. Cells were cultured for 24 hours, scored for syncytia formation and the cell lysate was assayed for luciferase production (Promega, Madison, WI, USA), which was measured with a luminometer. The output was expressed as relative light units (RLU).

\section{Acknowledgements}

We thank Merck research laboratories (Michael Miller) for providing us with the D5-lgGI antibody and Trimeris for providing us with the T20 peptide. Soluble CD4 from Dr. Norbert Schuelke was obtained through the NIH AIDS research and reference reagent program, Division of AIDS, NIAID, NIH. We thank Rogier Sanders and Dirk Eggink for critical reading of the manuscript. We also would like to thank llya Bontjer and Stef Heymen for technical assistance. This research was supported by grant number 200502 I from the AIDS fund (Amsterdam).

\section{References}

I. Eckert DM, Kim PS: Mechanisms of viral membrane fusion and its inhibition. Annu Rev Biochem 200I, 70:777-8I0.

2. Weissenhorn W, Dessen A, Harrison SC, Skehel JJ, Wiley DC: Atomic structure of the ectodomain from HIV-I gp4I. Nature 1997, 387:426-430.

3. Tan K, Liu J, Wang J, Shen S, Lu M: Atomic structure of a thermostable subdomain of HIV-I gp4 I. Proc Natl Acad Sci USA 1997, 94: $12303-12308$.

4. Chan DC, Fass D, Berger JM, Kim PS: Core structure of gp4I from the HIV envelope glycoprotein. Cell 1997, 89:263-273.

5. Melikyan GB, Markosyan RM, Hemmati H, Delmedico MK, Lambert DM, Cohen FS: Evidence that the transition of HIV-I gp4I into a six-helix bundle, not the bundle configuration, induces membrane fusion. J Cell Biol 2000, I 5 I:4 I 3-423.

6. Jelesarov I, Lu M: Thermodynamics of trimer-of-hairpins formation by the SIV gp4I envelope protein. J Mol Biol 200I, 307:637-656.

7. Lu M, Blacklow SC, Kim PS: A trimeric structural domain of the HIV-I transmembrane glycoprotein. Nat Struct Biol 1995, 2:1075-1082.

8. Wild CT, Shugars DC, Greenwell TK, McDanal CB, Matthews T]: Peptides corresponding to a predictive alpha-helical domain of human immunodeficiency virus type I gp4I are potent inhibitors of virus infection. Proc Natl Acad Sci U S A 1994 , 91:9770-9774

9. Chen SS: Functional role of the zipper motif region of human immunodeficiency virus type I transmembrane protein gp4I. J Virol 1994, 68:2002-2010.

10. Baldwin CE, Sanders RW, Berkhout B: Inhibiting HIV-I entry with fusion inhibitors. Curr Med Chem 2003, I 0:1633-1642.

II. Lazzarin A, Clotet B, Cooper D, Reynes J, Arasteh K, Nelson M, Katlama C, Stellbrink HJ, Delfraissy JF, Lange J, Huson L, DeMasi R, Wat C, Delehanty J, Drobnes C, Salgo M: Efficacy of enfuvirtide in patients infected with drug-resistant HIV-I in Europe and Australia. N Engl J Med 2003, 348:2 I86-2195.

12. Wild C, Dubay JW, Greenwell T, Baird T Jr., Oas TG, McDanal C, Hunter E, Matthews T: Propensity for a leucine zipper-like domain of human immunodeficiency virus type I gp4l to form oligomers correlates with a role in virus- induced fusion rather than assembly of the glycoprotein complex. Proc Natl Acad Sci U S A 1994, 91:12676-12680.

13. Kilgore NR, Salzwedel K, Reddick M, Allaway GP, Wild CT: Direct evidence that $C$-peptide inhibitors of human immunodeficiency virus type I entry bind to the gp4I N-helical domain in receptor-activated viral envelope. J Virol 2003, 77:7669-7672.

14. Reeves JD, Miamidian JL, Biscone MJ, Lee FH, Ahmad N, Pierson TC, Doms RW: Impact of mutations in the coreceptor binding site on human immunodeficiency virus type I fusion, infection, and entry inhibitor sensitivity. J Virol 2004, 78:5476-5485.

I5. Reeves JD, Gallo SA, Ahmad N, Miamidian JL, Harvey PE, Sharron M, Pohlmann S, Sfakianos JN, Derdeyn CA, Blumenthal R, Hunter E, Doms RW: Sensitivity of HIV-I to entry inhibitors correlates with envelope/coreceptor affinity, receptor density, and fusion kinetics. Proc Natl Acad Sci U S A 2002, 99: I 6249-I6254.

16. Alam SM, Paleos CA, Liao HX, Scearce R, Robinson J, Haynes BF: An inducible HIV type I gp4 I HR-2 peptide-binding site on HIV type I envelope gpI20. AIDS Res Hum Retroviruses 2004, 20:836-845.

17. Beddows S, Zheng NN, Herrera C, Michael E, Barnes K, Moore JP, Daniels RS, Weber JN: Neutralization sensitivity of HIV-I Envpseudotyped virus clones is determined by co-operativity between mutations which modulate the CD4-binding site and those that affect gpI20-gp4I stability. Virol 2005, 337:136-148.

18. Liu S, Lu H, Niu J, Xu Y, Wu S, Jiang S: Different from the HIV fusion inhibitor $\mathrm{C34}$, the anti-HIV drug Fuzeon (T-20) inhibits HIV-I entry by targeting multiple sites in gp4 I and gp I 20. J Biol Chem 2005, 280: I I 259- I 1273.

19. Wei X, Decker JM, Liu H, Zhang Z, Arani RB, Kilby JM, Saag MS, Wu $X$, Shaw GM, Kappes JC: Emergence of resistant human immunodeficiency virus type $I$ in patients receiving fusion inhibitor (T-20) monotherapy. Antimicrob Agents Chemother 2002, 46: $1896-1905$.

20. Baldwin CE, Sanders RW, Deng $Y$, Jurriaans S, Lange JM, Lu M, Berkhout B: Emergence of a drug-dependent human immunodeficiency virus type I variant during therapy with the T20 fusion inhibitor. J Virol 2004, 78: I 2428-I2437.

21. Kilby JM, Lalezari JP, Eron JJ, Carlson M, Cohen C, Arduino RC Goodgame JC, Gallant JE, Volberding P, Murphy RL, Valentine F, Saag MS, Nelson EL, Sista PR, Dusek A: The safety, plasma pharmacokinetics, and antiviral activity of subcutaneous enfuvirtide (T-20), a peptide inhibitor of gp 41 -mediated virus fusion, in HIV-infected adults. AIDS Res Hum Retroviruses 2002, I 8:685-693.

22. Poveda E, Rodes B, Toro C, Martin-Carbonero L, Gonzalez-Lahoz J Soriano V: Evolution of the gp4I env region in HIV-infected patients receiving $\mathbf{T}-\mathbf{2 0}$, a fusion inhibitor. AIDS 2002, 16:1959-1961.

23. Xu L, Pozniak A, Wildfire A, Stanfield-Oakley SA, Mosier SM, Ratcliffe D, Workman J, Joall A, Myers R, Smit E, Cane PA, Greenberg ML, Pillay $D$ : Emergence and evolution of enfuvirtide resistance following long-term therapy involves heptad repeat 2 mutations within gp4l. Antimicrob Agents Chemother 2005, 49: I | |3-I II9.

24. Perez-Alvarez L, Carmona R, Ocampo A, Asorey A, Miralles C, Perez C, Pinilla M, Contreras G, Taboada JA, Najera R: Long-term monitoring of genotypic and phenotypic resistance to $\mathrm{T} 20$ in treated patients infected with HIV-I. J Med Virol 2006, 78: $14 \mid-147$

25. Greenberg ML, Cammack N: Resistance to enfuvirtide, the first HIV fusion inhibitor. J Antimicrob Chemother 2004, 54:333-340.

26. Menzo S, Castagna A, Monachetti A, Hasson H, Danise A, Carini E, Bagnarelli $P$, Lazzarin A, Clementi M: Genotype and phenotype patterns of human immunodeficiency virus type I resistance to enfuvirtide during long-term treatment. Antimicrob Agents Chemother 2004, 48:3253-3259.

27. Sista PR, Melby T, Davison D, Jin L, Mosier S, Mink M, Nelson EL, DeMasi R, Cammack N, Salgo MP, Matthews TJ, Greenberg ML: Characterization of determinants of genotypic and phenotypic resistance to enfuvirtide in baseline and on-treatment HIV-I isolates. AIDS 2004, I 8: I787-I794.

28. Lu J, Sista P, Giguel F, Greenberg M, Kuritzkes DR: Relative replicative fitness of human immunodeficiency virus type I mutants resistant to enfuvirtide (T-20). J Virol 2004, 78:4628-4637.

29. Klaver B, Berkhout B: Evolution of a disrupted TAR RNA hairpin structure in the HIV-I virus. EMBO J I994, I 3:2650-2659.

30. Abbink TEM, Beerens N, Berkhout $B$ : Forced selection of a human immunodeficiency virus type $I$ variant that uses a non-self tRNA primer for reverse transcription: involvement of viral RNA sequences and the reverse transcriptase enzyme. J Virol 2004, 78: 10706-10714. 
31. Olsthoorn RCL, van Duin J: Evolutionary reconstruction of a hairpin deleted from the genome of an RNA virus. Proc Natl Acad Sci USA 1996, 93: 12256-I226I.

32. Lasky LA, Nakamura G, Smith DH, Fennie C, Shimasaki C, Patzer E, Berman P, Gregory T, Capon DJ: Delineation of a region of the human immunodeficiency virus type I gp I20 glycoprotein critical for interaction with the CD4 receptor. Cell 1987, 50:975-985

33. Cordonnier A, Montagnier L, Emerman M: Single amino-acid changes in HIV envelope affect viral tropism and receptor binding. Nature 1989, 340:57I-574.

34. Olshevsky U, Helseth E, Furman C, Li J, Haseltine W, Sodroski J: Identification of individual human immunodeficiency virus type I gp I 20 amino acids important for CD4 receptor binding. J Virol 1990, 64:5701-5707.

35. Robey FA, Harris-Kelson T, Robert-Guroff M, Batinic D, Ivanov B, Lewis MS, Roller PP: A synthetic conformational epitope from the C4 domain of HIV gp I 20 that binds CD4. J Biol Chem 1996, 27 I: I7990-I7995.

36. Cormier EG, Tran DN, Yukhayeva L, Olson WC, Dragic T: Mapping the determinants of the CCR5 amino-terminal sulfopeptide interaction with soluble human immunodeficiency virus type I gp I 20-CD4 complexes. J Virol 200 I, 75:554|-5549.

37. Kwong PD, Wyatt R, Robinson J, Sweet RW, Sodroski J, Hendrickson WA: Structure of an HIV gp I 20 envelope glycoprotein in a complex with the CD4 receptor and a neutralizing human antibody. Nature 1998, 393:648-659.

38. Rizzuto CD, Wyatt R, Hernandez-Ramos N, Sun Y, Kwong PD, Hendrickson WA, Sodroski J: A conserved HIV gp 20 glycoprotein structure involved in chemokine receptor binding. Science 1998, 280:1949-1953.

39. Daar ES, Li LX, Moudgil T, Ho DD: High concentrations of recombinant soluble CD4 are required to neutralize primary human immunodeficiency virus type I isolates. Proc Natl Acad Sci USA 1990, 87:6574-6578.

40. Miller MD, Geleziunas R, Bianchi E, Lennard S, Hrin R, Zhang H, Lu M, An Z, Ingallinella P, Finotto M, Mattu M, Finnefrock AC, Bramhill D, Cook J, Eckert DM, Hampton R, Patel M, Jarantow S, Joyce J, Ciliberto G, Cortese R, Lu P, Strohl W, Schleif W, McElhaugh M, Lane S, Lloyd C, Lowe D, Osbourn J, Vaughan T, Emini E, Barbato G, Kim PS, Hazuda DJ, Shiver JW, Pessi A: A human monoclonal antibody neutralizes diverse HIV-I isolates by binding a critical gp4 I epitope. Proc Natl Acad Sci U S A 2005, I 02: |4759-| 4764.

4I. Keulen W, Boucher C, Berkhout B: Nucleotide substitution patterns can predict the requirements for drug-resistance of HIV-I proteins. Antiviral Res 1996, 3 I:45-57.

42. Keulen W, Back NKT, van Wijk A, Boucher CAB, Berkhout B: Initial appearance of the I84Ile variant in lamivudine-treated patients is caused by the mutational bias of the human immunodeficiency virus type I Reverse Transcriptase. J Virol |997, 71:3346-3350.

43. Berkhout B, Das AT, Beerens N: HIV-I RNA editing, hypermutation and error-prone reverse transcription. Science 200I, 292:7-7.

44. Das AT, van Dam AP, Klaver B, Berkhout B: Improved envelope function selected by long-term cultivation of a translationimpaired HIV-I mutant. Virol 1998, 244:552-562.

45. Das AT, Land A, Braakman I, Klaver B, Berkhout B: HIV-I evolves into a non-syncytium-inducing virus upon prolonged culture in vitro. Virol 1999, 263:55-69.

46. Kowalski M, Potz J, Basiripour L, Dorfman T, Chun Goh W, Terwilliger E, Dayton A, Rosen C, Haseltine W, Sodroski J: Functional regions of the envelope glycoprotein of human immunodeficiency virus type I. Science 1987, 237:|35|-I355.

47. Verhoef K, Marzio G, Hillen W, Bujard H, Berkhout B: Strict control of human immunodeficiency virus type I replication by a genetic switch: Tet for Tat. J Virol 200I, 75:979-987.

48. Das AT, Baldwin CE, Vink M, Berkhout B: Improving the safety of a conditional-live human immunodeficiency virus type I vaccine by controlling both gene expression and cell entry. J Virol 2005, 79:3855-3858.

49. Jeeninga RE, Van der Linden B, Jan B, Van den Berg H, Berkhout B: Construction of a minimal HIV-I variant that selectively replicates in leukemic derived T-cell lines: towards a new virotherapy approach. Cancer Res 2005, 65:3347-3355.
50. Peden K, Emerman M, Montagnier L: Changes in growth properties on passage in tissue culture of viruses derived from infectious molecular clones of HIV-ILAI, HIV-IMAL, and HIVIELI. Virol |99|, | 85:66|-672.

5I. Sanders RW, Busser E, Moore JP, Lu M, Berkhout B: Evolutionary repair of HIV type I gp4I with a kink in the $\mathrm{N}$-terminal helix leads to restoration of the six-helix bundle structure. AIDS Res Hum Retroviruses 2004, 20:742-749.
Publish with Bio Med Central and every scientist can read your work free of charge

"BioMed Central will be the most significant development for disseminating the results of biomedical research in our lifetime. "

Sir Paul Nurse, Cancer Research UK

Your research papers will be:

- available free of charge to the entire biomedical community

- peer reviewed and published immediately upon acceptance

- cited in PubMed and archived on PubMed Central

- yours - you keep the copyright
BiolMedcentral 